\title{
Low-temperature synthesis of boride powders by controlling microstructure in precursor using organic compounds
}

\author{
Masaki KAKIAGE ${ }^{1, \dagger}$ \\ ${ }^{1}$ Institute for Fiber Engineering, Shinshu University (IFES), Interdisciplinary Cluster for Cutting Edge Research (ICCER), \\ Shinshu University, 3-15-1 Tokida, Ueda, Nagano 386-8567, Japan
}

The carbothermal reduction of boron oxide $\left(\mathrm{B}_{2} \mathrm{O}_{3}\right)$ is an important process for the synthesis of boride powders. As a low-temperature synthesis method for boron carbide $\left(\mathrm{B}_{4} \mathrm{C}\right)$ powder by carbothermal reduction, we focused on an approach using a condensed product prepared from boric acid $\left(\mathrm{H}_{3} \mathrm{BO}_{3}\right)$ and an organic compound with a number of hydroxyl groups (a polyol) such as glycerin, mannitol, or poly(vinyl alcohol). A borate ester bond was formed by the dehydration condensation of $\mathrm{H}_{3} \mathrm{BO}_{3}$ and a polyol, leading to the homogeneous dispersion of the boron and carbon sources at the molecular level. The thermal decomposition of a condensed $\mathrm{H}_{3} \mathrm{BO}_{3}$-polyol product in air was performed to control the amount of carbon to the stoichiometric $C / \mathrm{B}_{2} \mathrm{O}_{3}$ ratio required for carbothermal reduction. Within the thermally decomposed product consisting of $\mathrm{B}_{2} \mathrm{O}_{3}$ and carbon components $\left(\mathrm{B}_{4} \mathrm{C}\right.$ precursor), a $\mathrm{B}_{2} \mathrm{O}_{3}$ /carbon structure at the nanometer scale was formed. The improved dispersibility and homogeneity of the $\mathrm{B}_{2} \mathrm{O}_{3}$ /carbon microstructure accelerated the $\mathrm{B}_{4} \mathrm{C}$ formation at a lower temperature. Consequently, crystalline $\mathrm{B}_{4} \mathrm{C}$ powder with little free carbon was synthesized by heat treatment at a low temperature of $1200^{\circ} \mathrm{C}$ in an Ar flow. This low-temperature synthesis approach was applied to the lowtemperature synthesis of other boride powders, i.e., boron nitride and calcium hexaboride powders.

(๑2018 The Ceramic Society of Japan. All rights reserved.

Key-words: Low-temperature synthesis, Carbothermal reduction, Precursor, Microstructure, Polyol, Boron carbide $\left(\mathrm{B}_{4} \mathrm{C}\right)$, Boride powders

[Received April 28, 2018; Accepted May 28, 2018]

\section{Introduction}

Carbothermal reduction is an important industrial process for the synthesis of non-oxide ceramic powders such as carbides, borides, and nitrides. The carbothermal reduction of boron oxide $\left(\mathrm{B}_{2} \mathrm{O}_{3}\right)$ is the most common industrial manufacturing method for boron carbide $\left(\mathrm{B}_{4} \mathrm{C}\right)$ powder. ${ }^{1-3)}$ The overall reaction of carbothermal reduction is given by

$$
2 \mathrm{~B}_{2} \mathrm{O}_{3}+7 \mathrm{C} \rightarrow \mathrm{B}_{4} \mathrm{C}+6 \mathrm{CO} \text {. }
$$

This process is suitable for large-scale synthesis because the starting materials, which include boric acid $\left(\mathrm{H}_{3} \mathrm{BO}_{3}\right)$ or $\mathrm{B}_{2} \mathrm{O}_{3}$ as a boron source and activated carbon or petroleum coke as a carbon source, are inexpensive and nonhazardous. However, this process is conducted at a high temperature of approximately $2000^{\circ} \mathrm{C}$. The volatilization loss of boron components is significant at the high synthesis temperature. Furthermore, the obtained ingot must be crushed, refined, and granulated to produce $\mathrm{B}_{4} \mathrm{C}$ powder suitable for practical use. $\mathrm{B}_{4} \mathrm{C}$ exhibits extremely high

\footnotetext{
Corresponding author: M. Kakiage; E-mail: kakiage@ shinshu-u.ac.jp
}

hardness, and thus a large amount of energy is required for the pulverization process. Therefore, the development of a low-temperature synthetic route has been strongly expected for avoiding the volatilization loss of boron components and reducing the manufacturing cost.

In order to reduce the synthesis temperature of $\mathrm{B}_{4} \mathrm{C}$ powder by carbothermal reduction, the $\mathrm{B}_{2} \mathrm{O}_{3}$ and carbon components must be dispersed well to increase the contact area between the $\mathrm{B}_{2} \mathrm{O}_{3}$ and carbon components and to reduce the diffusion distance of the reacting species. Many studies reported to synthesize $\mathrm{B}_{4} \mathrm{C}$ powder at lower temperatures by using a condensed product which employed various organic compounds as a carbon source such as glycerin, ${ }^{4), 5)}$ citric acid, ${ }^{6)-8)}$ sugar, ${ }^{9), 10)}$ phenolic resin, ${ }^{11)}$ and poly(vinyl alcohol) (PVA), ${ }^{12)}$ and they could reduce the synthesis temperature to $1500-1600^{\circ} \mathrm{C}$. However, in the case of heat treatment at lower temperatures of less than $1500^{\circ} \mathrm{C}$, the product contained residual free carbon derived from the organic compound used as the raw material.

We have focused on both a molecular approach and a structural approach to further reduce the synthesis temperature of $\mathrm{B}_{4} \mathrm{C}$ powder without residual free carbon using a condensed $\mathrm{H}_{3} \mathrm{BO}_{3}$-polyol product. ${ }^{13)-19)}$ The compatibility of the composition, the dispersibility, and the homogeneity 
of the $\mathrm{B}_{2} \mathrm{O}_{3}$ and carbon components in a precursor was achieved by the combination of the bond-forming reaction between $\mathrm{H}_{3} \mathrm{BO}_{3}$ and a polyol and a thermal decomposition process in air (molecular approach). Furthermore, a finely and homogeneously arranged $\mathrm{B}_{2} \mathrm{O}_{3}$ /carbon structure in the precursor leaded to a larger interface between the $\mathrm{B}_{2} \mathrm{O}_{3}$ and carbon components, enabling synthesis of $\mathrm{B}_{4} \mathrm{C}$ powder at a low temperature of $1200^{\circ} \mathrm{C}$ (structural approach).

\section{Molecular approach: formation of $\mathrm{B}-\mathrm{O}-\mathrm{C}$ bond and compositional control by thermal decomposition in air}

Carbothermal reduction using a condensed product as a precursor that consists of $\mathrm{H}_{3} \mathrm{BO}_{3}$ and an organic compound with a number of hydroxyl $(-\mathrm{OH})$ groups (a polyol) is attractive as a low-temperature synthetic method for $\mathrm{B}_{4} \mathrm{C}$. A condensed $\mathrm{H}_{3} \mathrm{BO}_{3}$-polyol product forms a borate ester (B-O-C) bond by a dehydration condensation reaction between $\mathrm{H}_{3} \mathrm{BO}_{3}$ and the polyol [Fig. 1(a)]. ${ }^{20)}$ The formation of this bond leads to the homogeneous dispersion of the boron source and carbon source at the molecular level, and thus the synthesis temperature is reduced owing to the increased surface-active area between the $\mathrm{B}_{2} \mathrm{O}_{3}$ and carbon components with superior reactivity. We used glycerin $\left(\mathrm{C}_{3} \mathrm{H}_{8} \mathrm{O}_{3}\right),{ }^{14), 19)}$ mannitol $\left(\mathrm{C}_{6} \mathrm{H}_{14} \mathrm{O}_{6}\right),{ }^{16)}$ or $\mathrm{PVA}^{13), 15), 18)}$ as a polyol that has a strong complexation ability and can easily form a $\mathrm{B}-\mathrm{O}-\mathrm{C}$ bond with $\mathrm{H}_{3} \mathrm{BO}_{3}{ }^{5), 20), 21)}$ Expected molecular structures of a condensed $\mathrm{H}_{3} \mathrm{BO}_{3}$-glycerin product, ${ }^{5)}$ a condensed $\mathrm{H}_{3} \mathrm{BO}_{3}$-mannitol product, ${ }^{20)}$ and a condensed $\mathrm{H}_{3} \mathrm{BO}_{3}$-PVA product are shown in Fig. 1. However, the obtained product contained a large amount of residual carbon derived from the polyol, which is a common disadvantage of $\mathrm{B}_{4} \mathrm{C}$ synthesis using an organic compound, since a condensed product has excessively large carbon component compared with that required for carbothermal reduction. In previous research, ${ }^{8), 10)}$ an excessive amount of $\mathrm{H}_{3} \mathrm{BO}_{3}$ was used as a raw material to prevent the formation of residual free carbon in the product. However, the homogeneity was low for the condensed product prepared

(a)

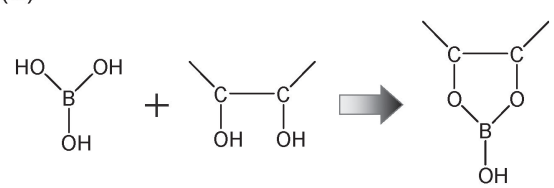

(b)

(c)
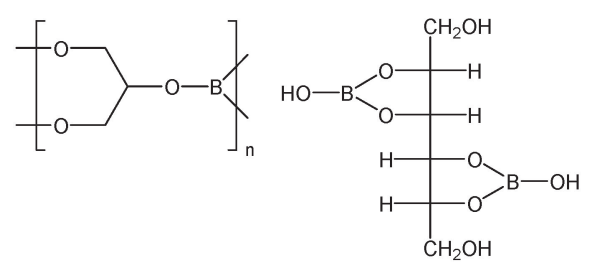

(d)<smiles>CCCC1CC(CC)OB(O)O1</smiles>

Fig. 1. (a) Schematic interpretation of dehydration condensation reaction between $\mathrm{H}_{3} \mathrm{BO}_{3}$ and polyol and molecular structures of (b) condensed $\mathrm{H}_{3} \mathrm{BO}_{3}$-glycerin product, (c) condensed $\mathrm{H}_{3} \mathrm{BO}_{3}$ mannitol product, and (d) condensed $\mathrm{H}_{3} \mathrm{BO}_{3}$-PVA product. with excess $\mathrm{H}_{3} \mathrm{BO}_{3}$, which contained an isolated $\mathrm{H}_{3} \mathrm{BO}_{3}$ component without a B-O-C bond. ${ }^{16)}$ Therefore, the simultaneous pursuit of dispersibility and compositional control of a condensed product contains a major contradiction.

In an attempt to resolve the above contradiction, we performed the thermal decomposition in air before the carbothermal reduction of a condensed $\mathrm{H}_{3} \mathrm{BO}_{3}$-polyol product prepared at the stoichiometric ratio for the dehydration condensation to control the amount of carbon to the stoichiometric $\mathrm{C} / \mathrm{B}_{2} \mathrm{O}_{3}$ ratio required for the carbothermal reduction given by Eq. (1) $\left(\mathrm{C} / \mathrm{B}_{2} \mathrm{O}_{3}=3.5\right)$. The thermal decomposition in air eliminates the excess carbon component while maintaining the dispersibility. Figure 2 shows X-ray diffraction (XRD) patterns of the products obtained by heat treatment at $1250^{\circ} \mathrm{C}$ for $5 \mathrm{~h}$ in an Ar flow of thermally decomposed products (precursor powders) prepared from the condensed $\mathrm{H}_{3} \mathrm{BO}_{3}$-mannitol product by thermal decomposition at (a) $300-500^{\circ} \mathrm{C}$ for $2 \mathrm{~h}$ and (b) $400^{\circ} \mathrm{C}$ for $1-4 \mathrm{~h}$ in air. ${ }^{16)}$ The XRD patterns changed systematically with the thermal decomposition temperature [Fig. 2(a)] and holding time [Fig. 2(b)]. A peak attributed to amorphous carbon was observed at lower thermal decomposition temperatures or for shorter holding times, indicating that the precursor had excess carbon, and peaks attributed to $\mathrm{B}_{2} \mathrm{O}_{3}$ were observed at higher thermal decomposition temperatures or for longer holding times, indicating that the precursor had excess $\mathrm{B}_{2} \mathrm{O}_{3}$. Note that the structural homogeneity of the condensed $\mathrm{H}_{3} \mathrm{BO}_{3}$-mannitol product dominated the $\mathrm{B}_{4} \mathrm{C}$ formation behavior at a low synthesis temperature (see Figs. 11 and 12 in Ref. 16). The formation of $\mathrm{B}_{4} \mathrm{C}$ was induced simultaneously within a short time throughout the entire homogeneous precursor (the thermally decomposed product prepared from the condensed product with the stoichiometric ratio for the dehydration condensation) even at a low synthesis temperature. In contrast, widely spaced $\mathrm{B}_{2} \mathrm{O}_{3}$ and carbon components, which have less reactivity, existed in the heterogeneous precursor (the condensed product prepared with excess $\mathrm{H}_{3} \mathrm{BO}_{3}$, which contained an isolated $\mathrm{H}_{3} \mathrm{BO}_{3}$ component without a $\mathrm{B}-\mathrm{O}-\mathrm{C}$ bond). The heterogeneity of the synthesis reaction, which reflects the structural heterogeneity, resulted in a time lag in the complete formation of $\mathrm{B}_{4} \mathrm{C}$, particularly at a low synthesis temperature. ${ }^{16)}$ Consequently, the low-temperature synthesis of crystalline $\mathrm{B}_{4} \mathrm{C}$ powder with little free carbon was achieved by carbothermal reduction using a condensed $\mathrm{H}_{3} \mathrm{BO}_{3}$-polyol product with a highly and homogeneously dispersed structure and a suitable $\mathrm{C} / \mathrm{B}_{2} \mathrm{O}_{3}$ composition. The $\mathrm{C} / \mathrm{B}_{2} \mathrm{O}_{3}$ composition of the precursor can be controlled by varying the thermal decomposition conditions in air.

\section{Structural approach: morphological control of $\mathrm{B}_{2} \mathrm{O}_{3}$ /carbon microstructure in precursor}

The formation reaction of $\mathrm{B}_{4} \mathrm{C}$ from a condensed $\mathrm{H}_{3} \mathrm{BO}_{3}$-polyol product is carbothermal reduction, i.e., the reaction of $\mathrm{B}_{2} \mathrm{O}_{3}$ and carbon [Eq. (1)]. Hence, we propose an approach to developing lower-temperature synthesis routes by clarifying in detail the relation between the 

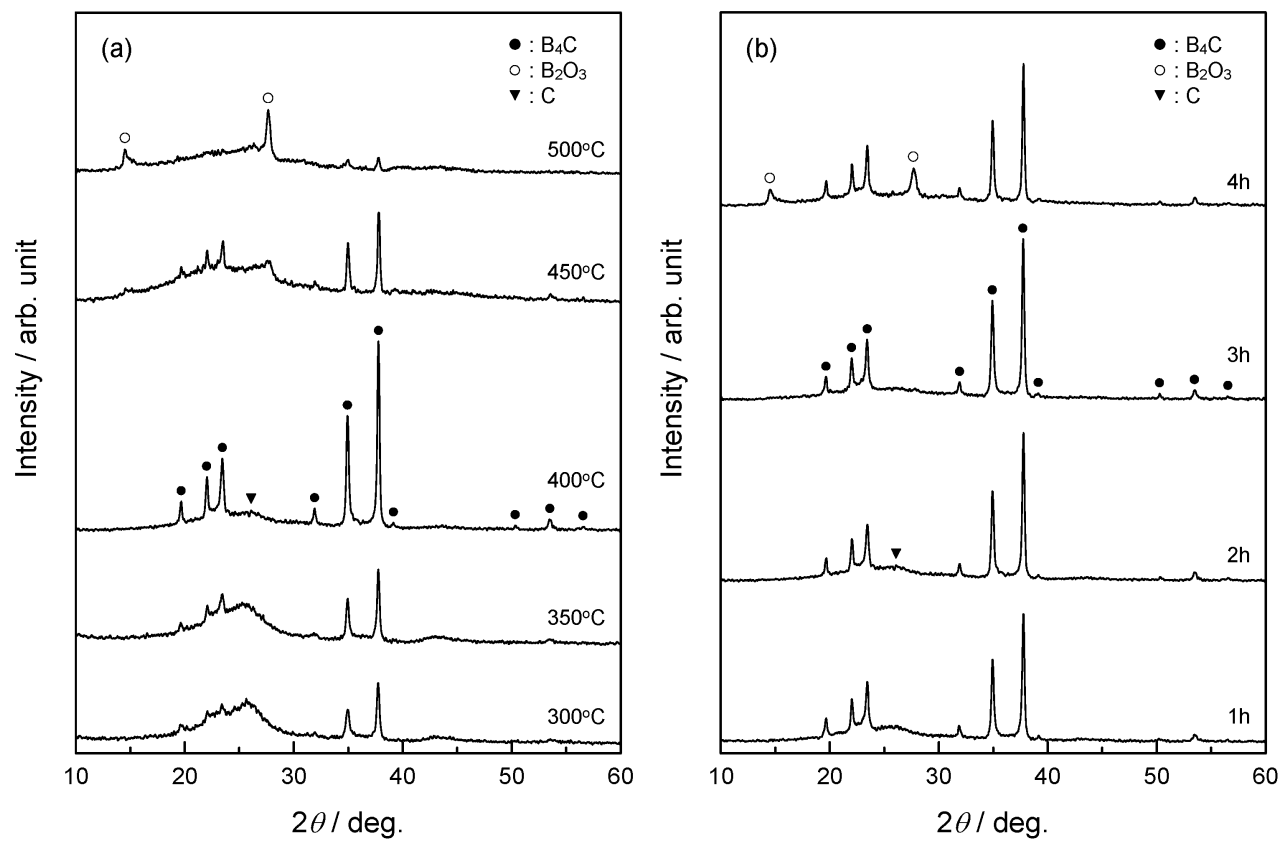

Fig. 2. XRD patterns of products obtained by heat treatment at $1250^{\circ} \mathrm{C}$ for $5 \mathrm{~h}$ in an Ar flow of precursor powders prepared from condensed $\mathrm{H}_{3} \mathrm{BO}_{3}$-mannitol product by thermal decomposition at (a) $300-500^{\circ} \mathrm{C}$ for $2 \mathrm{~h}$ and (b) $400^{\circ} \mathrm{C}$ for $1-4 \mathrm{~h}$ in air. ${ }^{16)}$

precursor structure $\left(\mathrm{B}_{2} \mathrm{O}_{3} /\right.$ carbon structure $)$ and the formation of $\mathrm{B}_{4} \mathrm{C}$.

A thermally decomposed product consisting of $\mathrm{B}_{2} \mathrm{O}_{3}$ and carbon components $\left(\mathrm{B}_{4} \mathrm{C}\right.$ precursor) was prepared from a condensed $\mathrm{H}_{3} \mathrm{BO}_{3}$-polyol product by thermal decomposition in air. Within the obtained precursor prepared from the condensed $\mathrm{H}_{3} \mathrm{BO}_{3}$-polyol product under suitable conditions, a three-dimensional networked carbon structure with a homogeneous $\mathrm{B}_{2} \mathrm{O}_{3}$ /carbon arrangement at the nanometer scale was spontaneously formed. Figure 3 shows scanning electron microscope (SEM) images of the precursors prepared from $(a, b)$ the condensed $\mathrm{H}_{3} \mathrm{BO}_{3}$ glycerin product ${ }^{14)}$ and (c, d) the condensed $\mathrm{H}_{3} \mathrm{BO}_{3}-\mathrm{PVA}$ product. ${ }^{15)}$ The $\mathrm{B}_{2} \mathrm{O}_{3}$ component can be removed by washing the precursor powder in hot water, thus leaving the carbon component, as shown in Figs. 3(b) and 3(d). A characteristic carbon network structure with nano-order spacing can be recognized for both precursors. A threedimensional bicontinuous structure composed of $\mathrm{B}_{2} \mathrm{O}_{3}$ and carbon components was formed for the condensed $\mathrm{H}_{3} \mathrm{BO}_{3}$ glycerin product [Fig. 3(b)]. On the other hand, nanosize $\mathrm{B}_{2} \mathrm{O}_{3}$ particles were dispersed in a carbon matrix for the condensed $\mathrm{H}_{3} \mathrm{BO}_{3}-\mathrm{PVA}$ product [Fig. 3(d)]. The $\mathrm{B}_{2} \mathrm{O}_{3} /$ carbon microstructure is beneficial for the low-temperature carbothermal reduction of $\mathrm{B}_{2} \mathrm{O}_{3}$, coupled with the dispersibility of the boron and carbon sources. The formation of a homogeneously arranged $\mathrm{B}_{2} \mathrm{O}_{3}$ /carbon structure at the nanometer scale contributes to its markedly increased contact area without the powder compaction of the raw materials. Furthermore, the networked carbon structure prevents the aggregation of molten $\mathrm{B}_{2} \mathrm{O}_{3}$ liquid (melting point: $450^{\circ} \mathrm{C}$ ) during the heat treatment, leading to an enlarged surface-active area and the efficient removal of
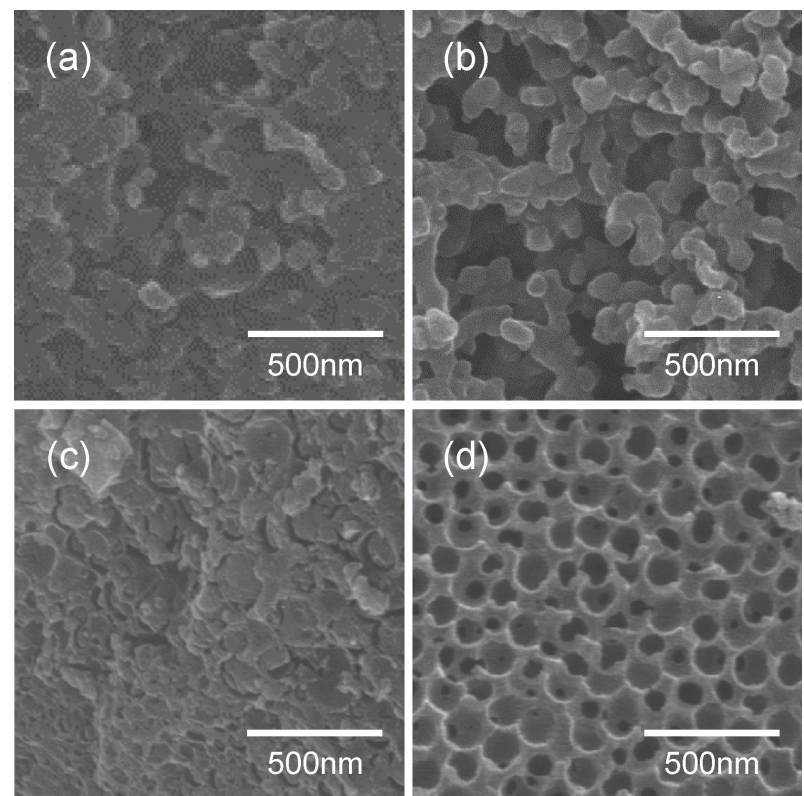

Fig. 3. SEM images of precursors prepared from $(\mathrm{a}, \mathrm{b})$ condensed $\mathrm{H}_{3} \mathrm{BO}_{3}$-glycerin product ${ }^{14)}$ and $(\mathrm{c}, \mathrm{d})$ condensed $\mathrm{H}_{3} \mathrm{BO}_{3}-$ PVA product ${ }^{15)}(\mathrm{a}, \mathrm{c})$ before and $(b, d)$ after removal of $\mathrm{B}_{2} \mathrm{O}_{3}$ by washing in hot water.

the byproduct $\mathrm{CO}$ gas. Therefore, the synthesis temperature is expected to be lowered by improving the dispersion state of the $\mathrm{B}_{2} \mathrm{O}_{3}$ and carbon components owing to the increased surface-active area between the $\mathrm{B}_{2} \mathrm{O}_{3}$ and carbon components, resulting in higher reactivity.

The precursor prepared from the condensed $\mathrm{H}_{3} \mathrm{BO}_{3}-$ glycerin product formed a characteristic three-dimensional bicontinuous structure composed of $\mathrm{B}_{2} \mathrm{O}_{3}$ and carbon 

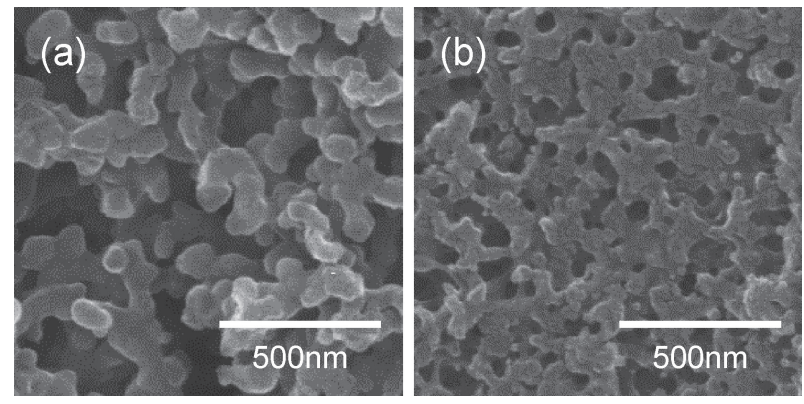

Fig. 4. SEM images of precursors prepared from condensed $\mathrm{H}_{3} \mathrm{BO}_{3}$-glycerin product (a) without and (b) with TA added after removal of $\mathrm{B}_{2} \mathrm{O}_{3}$ by washing in hot water. ${ }^{19)}$

components [Fig. 3(b)]. Glycerin is an organic solvent of low molecular weight; thus, homogeneous blending can be easily achieved with an organic compound. Therefore, we attempted to further develop the precursor structure by the multicomponent blending of organic compounds to obtain a precursor with a more homogenously and finely dispersed $\mathrm{B}_{2} \mathrm{O}_{3} /$ carbon structure derived from the condensed $\mathrm{H}_{3} \mathrm{BO}_{3}$-glycerin product. ${ }^{19)}$ Tartaric acid $\left(\mathrm{C}_{4} \mathrm{H}_{6} \mathrm{O}_{6}\right.$, $\mathrm{TA})$ was adopted as the organic compound added to the condensed $\mathrm{H}_{3} \mathrm{BO}_{3}$-glycerin product because of its two hydroxyl and two carboxyl groups, low molecular weight, and solubility in glycerin. Figure 4 shows SEM images of the precursors prepared from the condensed $\mathrm{H}_{3} \mathrm{BO}_{3}$ glycerin product (a) without and (b) with TA added after the removal of $\mathrm{B}_{2} \mathrm{O}_{3}$ by washing in hot water. ${ }^{19)}$ The precursor prepared from the condensed $\mathrm{H}_{3} \mathrm{BO}_{3}$-glycerin product with TA added [Fig. 4(b)] had a more homogeneously and finely dispersed bicontinuous $\mathrm{B}_{2} \mathrm{O}_{3} /$ carbon structure. This is because the hydroxyl groups enabled the chemical structure of the complex condensed product to be continuously formed, and the carboxyl groups separated the $\mathrm{H}_{3} \mathrm{BO}_{3}$ parts. Figure 5 shows XRD patterns of the products obtained by heat treatment of these precursor powders at $1250^{\circ} \mathrm{C}$ for $3 \mathrm{~h}$ in an Ar flow. ${ }^{19)}$ The complete formation of crystalline $\mathrm{B}_{4} \mathrm{C}$ powder was achieved at $1250^{\circ} \mathrm{C}$ within a shorter heat treatment time for the precursor with a fine dispersion state [Fig. 4(b)] because the diffusion of reacting species became easier with increasing contact area of the $\mathrm{B}_{2} \mathrm{O}_{3}$ and carbon components.

The morphology of the precursor obtained by the thermal decomposition of the condensed $\mathrm{H}_{3} \mathrm{BO}_{3}$-PVA product in air consisted of $\mathrm{B}_{2} \mathrm{O}_{3}$ particles dispersed in a carbon matrix [Fig. 3(d)], which is similar to the sea-island structure of a polymer alloy. It is known that the phaseseparated morphology of a polymer alloy is related to the volume fraction of each component. Furthermore, the number of hydroxyl groups, which react with $\mathrm{H}_{3} \mathrm{BO}_{3}$, increases with increasing PVA content, increasing the dispersion of $\mathrm{H}_{3} \mathrm{BO}_{3}$. Thus, we considered the effect of the PVA content of the condensed $\mathrm{H}_{3} \mathrm{BO}_{3}$-PVA product on the microstructure in the precursor and the formation of $\mathrm{B}_{4} \mathrm{C}$ at a low synthesis temperature. ${ }^{18)}$ Figure 6 shows SEM images of the precursors prepared from the condensed

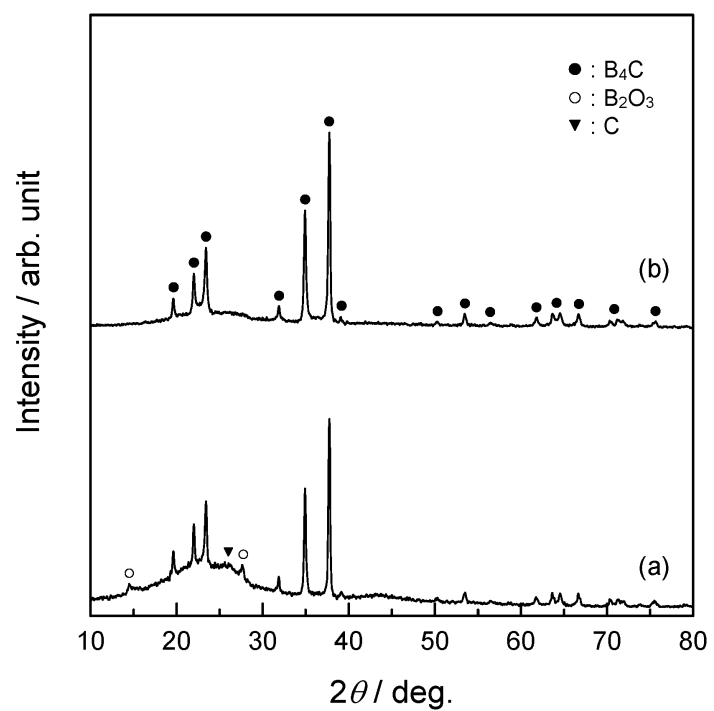

Fig. 5. XRD patterns of products obtained by heat treatment at $1250^{\circ} \mathrm{C}$ for $3 \mathrm{~h}$ in an Ar flow of precursor powders prepared from condensed $\mathrm{H}_{3} \mathrm{BO}_{3}$-glycerin product (a) without and (b) with TA added (corresponding to Fig. 4). ${ }^{19)}$
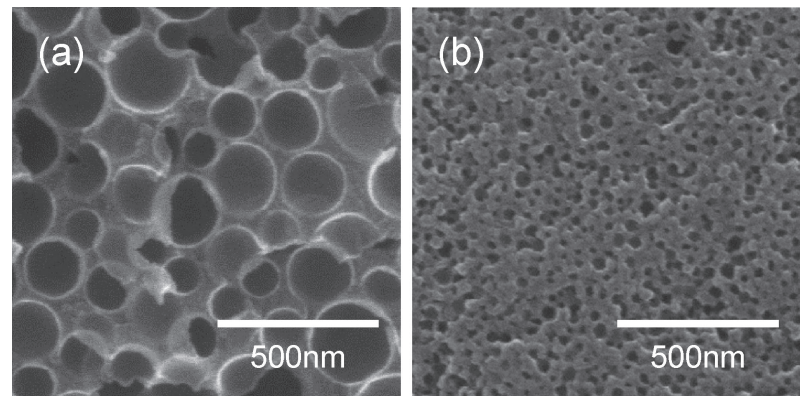

Fig. 6. SEM images of precursors prepared from condensed $\mathrm{H}_{3} \mathrm{BO}_{3}$-PVA product with (a) lower and (b) higher PVA contents after removal of $\mathrm{B}_{2} \mathrm{O}_{3}$ by washing in hot water. ${ }^{18)}$

$\mathrm{H}_{3} \mathrm{BO}_{3}$-PVA product with (a) lower and (b) higher PVA contents after the removal of $\mathrm{B}_{2} \mathrm{O}_{3}$ by washing in hot water. ${ }^{18)}$ The dispersibility of $\mathrm{B}_{2} \mathrm{O}_{3}$ particles in the carbon matrix markedly improved with increasing PVA content of the condensed product. $\mathrm{H}_{3} \mathrm{BO}_{3}$ molecules were more finely dispersed in the network of the condensed product with increasing PVA content. Consequently, the aggregation of $\mathrm{B}_{2} \mathrm{O}_{3}$ was suppressed and a precursor having a finely and homogeneously dispersed structure was fabricated. Figure 7 shows XRD patterns of the products obtained by heat treatment of these precursor powders at $1200^{\circ} \mathrm{C}$ for $5 \mathrm{~h}$ in an Ar flow. ${ }^{18)}$ Crystalline $\mathrm{B}_{4} \mathrm{C}$ powder with little free carbon was synthesized at $1200^{\circ} \mathrm{C}$ for $5 \mathrm{~h}$ from the precursor with a more finely and homogeneously dispersed structure [Fig. 6(b)], which is the lowest temperature reported for the synthesis of $\mathrm{B}_{4} \mathrm{C}$ powder by carbothermal reduction. These results demonstrate that the synthesis temperature and holding time can be reduced by using a precursor with a finely and homogeneously dispersed $\mathrm{B}_{2} \mathrm{O}_{3}$ /carbon structure because the diffusion of the reacting species became easier with increasing contact 
area of the $\mathrm{B}_{2} \mathrm{O}_{3}$ and carbon components and decreasing diffusion distance of the reacting species.

Figure 8 shows SEM images and particle size distributions of the products obtained by heat treatment at $1250^{\circ} \mathrm{C}$ for $5 \mathrm{~h}$ in an Ar flow from $(\mathrm{a}, \mathrm{b})$ the condensed $\mathrm{H}_{3} \mathrm{BO}_{3}-$ mannitol product, ${ }^{16)}(\mathrm{c}, \mathrm{d})$ the condensed $\mathrm{H}_{3} \mathrm{BO}_{3}$-glycerin product, ${ }^{19)}$ and (e, f) the condensed $\mathrm{H}_{3} \mathrm{BO}_{3}$-PVA prod-

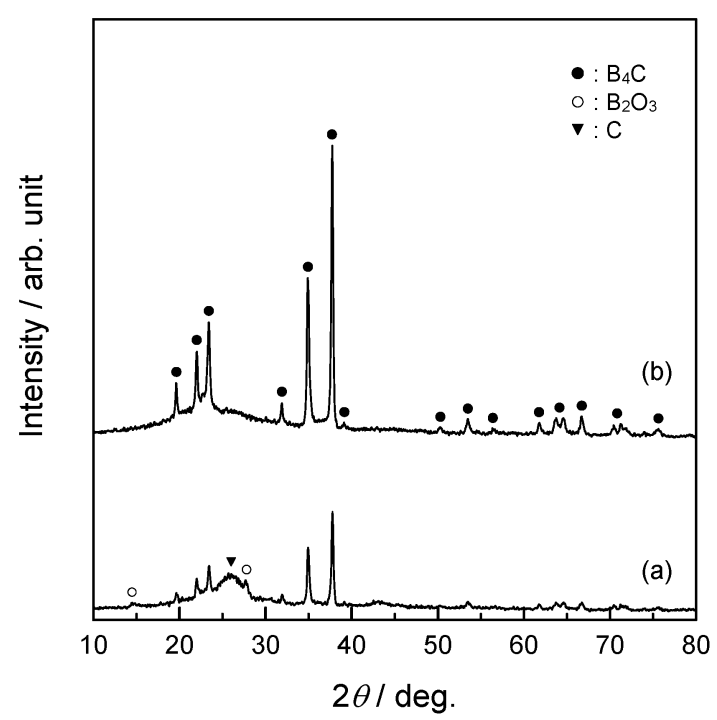

Fig. 7. XRD patterns of products obtained by heat treatment at $1200^{\circ} \mathrm{C}$ for $5 \mathrm{~h}$ in an $\mathrm{Ar}$ flow of precursor powders prepared from condensed $\mathrm{H}_{3} \mathrm{BO}_{3}$-PVA product with (a) lower and (b) higher PVA contents (corresponding to Fig. 6). ${ }^{18)}$ uct. ${ }^{18)} \mathrm{B}_{4} \mathrm{C}$ powder was obtained without a postgrinding process in each case. Interestingly, the particle size differs according to the polyol used. Fine $\mathrm{B}_{4} \mathrm{C}$ powder with submicrometer-size particles was obtained for the products prepared using mannitol $\left(D_{50}=0.8 \mu \mathrm{m}\right)$ and glycerin $\left(D_{50}=0.9 \mu \mathrm{m}\right)$. On the other hand, the grain growth of $\mathrm{B}_{4} \mathrm{C}$ particles was observed for the product prepared using PVA $\left(D_{50}=10.0 \mu \mathrm{m}\right)$. This result implies that the structural morphology of the precursor affected the morphology of the $\mathrm{B}_{4} \mathrm{C}$ particles. ${ }^{17)}$

\section{Application to low-temperature synthesis of other boride powders: $\mathrm{BN}$ and $\mathrm{CaB}_{6}$ powders}

Boron nitride $(\mathrm{BN})$ powder is obtained by the heat treatment of a compacted $\mathrm{B}_{2} \mathrm{O}_{3}$-carbon mixture (pellet) in a $\mathrm{N}_{2}$ flow (carbothermal nitridation), ${ }^{22)-25)}$ for which the overall reaction is given by

$$
\mathrm{B}_{2} \mathrm{O}_{3}+3 \mathrm{C}+\mathrm{N}_{2} \rightarrow 2 \mathrm{BN}+3 \mathrm{CO} \text {. }
$$

The $\mathrm{B}_{2} \mathrm{O}_{3} /$ carbon structure is beneficial for the lowtemperature synthesis of $\mathrm{BN}$ powder by carbothermal nitridation using $\mathrm{N}_{2}$ gas. The contact area of the $\mathrm{B}_{2} \mathrm{O}_{3}$, carbon, and $\mathrm{N}_{2}$ gas components is much larger than that obtained by conventional powder compaction. Furthermore, the networked carbon structure prevents the spread of molten $\mathrm{B}_{2} \mathrm{O}_{3}$ liquid. Figure 9 shows XRD patterns of the products obtained by heat treatment of the precursor powder prepared from the condensed $\mathrm{H}_{3} \mathrm{BO}_{3}-\mathrm{PVA}$ product and the directly mixed powder consisting of $\mathrm{B}_{2} \mathrm{O}_{3}$ and

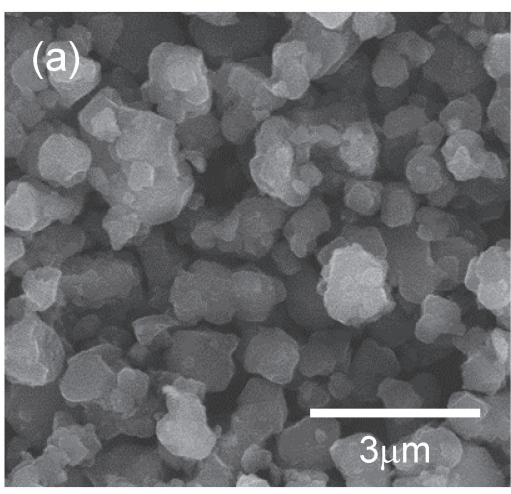

(b)

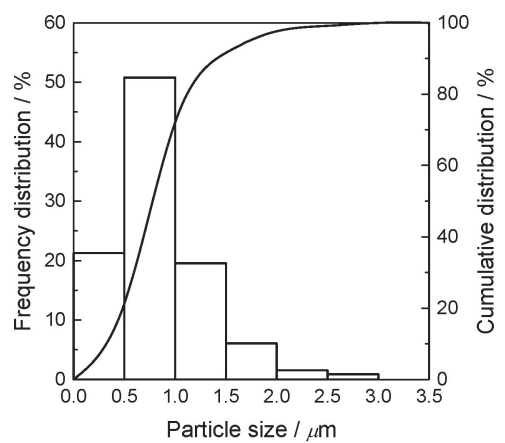

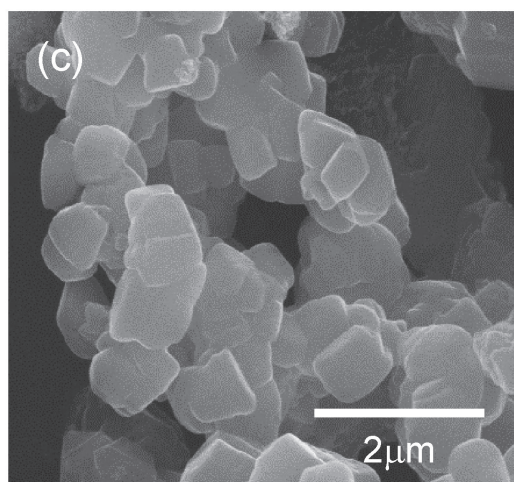

(d)

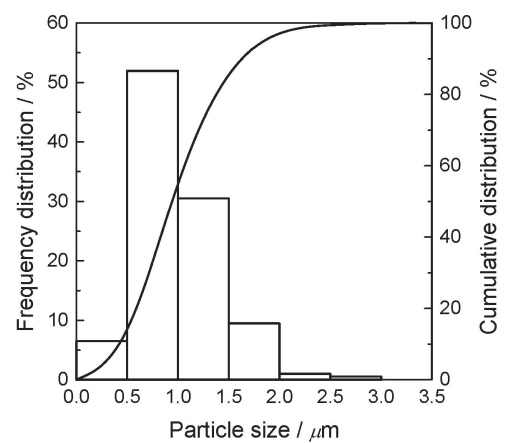

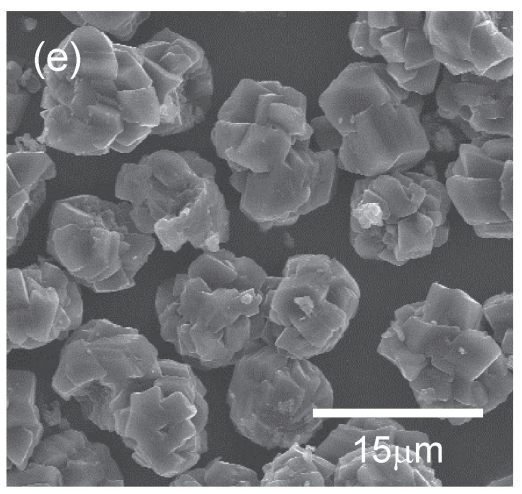

(f)

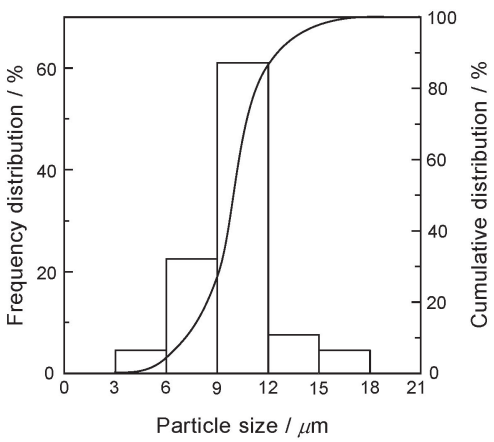

Fig. 8. SEM images and particle size distributions of products obtained by heat treatment at $1250^{\circ} \mathrm{C}$ for $5 \mathrm{~h}$ in an Ar flow from (a, b) condensed $\mathrm{H}_{3} \mathrm{BO}_{3}$-mannitol product, ${ }^{16)}$ (c, d) condensed $\mathrm{H}_{3} \mathrm{BO}_{3}$-glycerin product, ${ }^{19)}$ and (e, f) condensed $\mathrm{H}_{3} \mathrm{BO}_{3}-\mathrm{PVA}$ product. ${ }^{18)}$ 


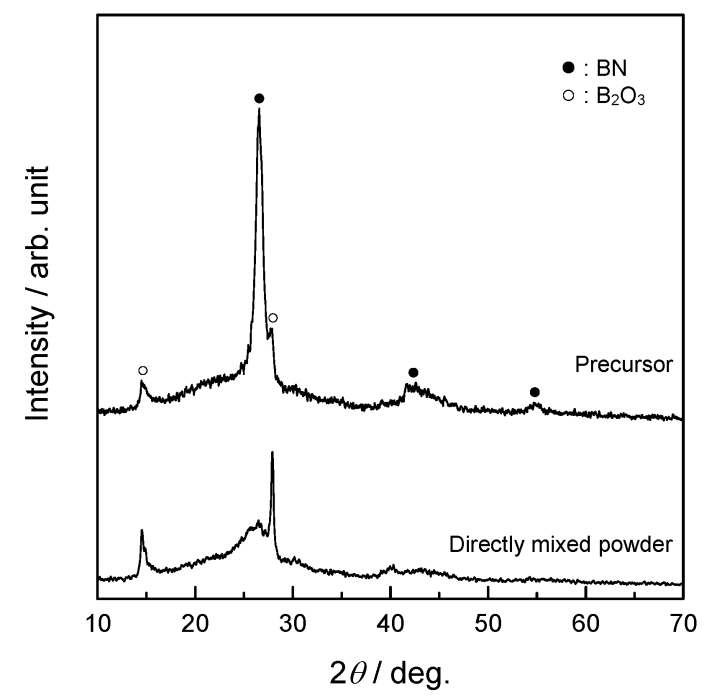

Fig. 9. XRD patterns of products obtained by heat treatment of precursor powder and directly mixed powder at $1200^{\circ} \mathrm{C}$ for $10 \mathrm{~h}$ in a $\mathrm{N}_{2}$ flow. ${ }^{26)}$

activated carbon at $1200^{\circ} \mathrm{C}$ for $10 \mathrm{~h}$ in a $\mathrm{N}_{2}$ flow. ${ }^{26)}$ The $\mathrm{BN}$ formation was accelerated for the product obtained from the precursor powder, which had a finely dispersed $\mathrm{B}_{2} \mathrm{O}_{3} /$ carbon structure. This demonstrates that the formation of the $\mathrm{B}_{2} \mathrm{O}_{3}$ /carbon structure is effective for the lowtemperature carbothermal nitridation.

Calcium hexaboride $\left(\mathrm{CaB}_{6}\right)$ powder is synthesized under vacuum at above $1400^{\circ} \mathrm{C}$ using calcium carbonate $\left(\mathrm{CaCO}_{3}\right), \mathrm{B}_{4} \mathrm{C}$, and carbon powders as starting materials $\left(\mathrm{B}_{4} \mathrm{C}\right.$ method). ${ }^{27)-29)}$ On the other hand, the formation of $\mathrm{CaB}_{6}$ by carbothermal reduction without the use of $\mathrm{B}_{4} \mathrm{C}$ requires a high synthesis temperature of above $1700^{\circ} \mathrm{C} .{ }^{30}$ ) Note that this process includes the transient formation of $\mathrm{B}_{4} \mathrm{C}$. Here, the formation temperature of $\mathrm{B}_{4} \mathrm{C}$ is high (above $1500^{\circ} \mathrm{C}$ ), suggesting that the transient formation of $\mathrm{B}_{4} \mathrm{C}$ is the rate-determining step in this process. Thus, we propose a new low-temperature synthesis approach for $\mathrm{CaB}_{6}$ powder without the use of $\mathrm{B}_{4} \mathrm{C}$ as a raw material by the carbothermal reduction of a calcium oxide $(\mathrm{CaO})$ $\mathrm{B}_{2} \mathrm{O}_{3}-\mathrm{C}$ system [Eq. (3)] using the above-mentioned lowtemperature synthesis method for $\mathrm{B}_{4} \mathrm{C}$ powder. ${ }^{31), 32)}$

$$
\mathrm{CaO}+3 \mathrm{~B}_{2} \mathrm{O}_{3}+10 \mathrm{C} \rightarrow \mathrm{CaB}_{6}+10 \mathrm{CO}
$$

Figure 10 shows XRD patterns of the products obtained by heat treatment of a mixture of the thermally decomposed product prepared from the condensed $\mathrm{H}_{3} \mathrm{BO}_{3}$-PVA product and $\mathrm{CaCO}_{3}$ powder and the directly mixed powder consisting of $\mathrm{CaCO}_{3}, \mathrm{~B}_{2} \mathrm{O}_{3}$, and activated carbon at $1400^{\circ} \mathrm{C}$ for $5 \mathrm{~h}$ in an Ar flow. ${ }^{31)}$ Peaks attributed to $\mathrm{CaB}_{6}$ were observed only for the product obtained using the thermally decomposed product, indicating that the $\mathrm{B}_{2} \mathrm{O}_{3} /$ carbon structure is essential for the formation of $\mathrm{CaB}_{6}$ at a lower temperature. The transient formation of $\mathrm{B}_{4} \mathrm{C}$ occurred at a low temperature of $1200^{\circ} \mathrm{C}^{31), 32)} \mathrm{CaB}_{6}$ was formed via the transient formation of calcium borate $\left(\mathrm{Ca}_{3} \mathrm{~B}_{2} \mathrm{O}_{6}\right)$ and $\mathrm{B}_{4} \mathrm{C},{ }^{31), 32}$ and $\mathrm{CaB}_{6}$ powder with fine

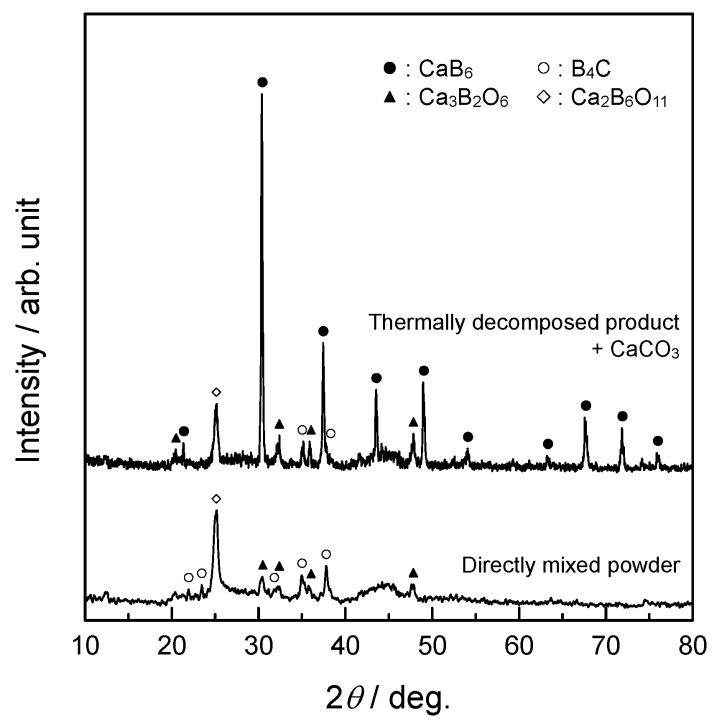

Fig. 10. XRD patterns of products obtained by heat treatment of mixture of thermally decomposed product and $\mathrm{CaCO}_{3}$ powder and directly mixed powder at $1400^{\circ} \mathrm{C}$ for $5 \mathrm{~h}$ in an Ar flow. ${ }^{31)}$

particles was synthesized by heat treatment at $1400^{\circ} \mathrm{C}$ for $3 \mathrm{~h}$ in an Ar flow. ${ }^{32)}$ These results demonstrate that the $\mathrm{B}_{2} \mathrm{O}_{3}$ /carbon structure prepared from a condensed $\mathrm{H}_{3} \mathrm{BO}_{3}$ polyol product by thermal decomposition in air is a suitable precursor for the low-temperature synthesis of boride powders by carbothermal reduction.

\section{Summary}

In this review, our approach to the low-temperature synthesis of boride powders, i.e., $\mathrm{B}_{4} \mathrm{C}, \mathrm{BN}$, and $\mathrm{CaB}_{6}$ powders, by controlling the $\mathrm{B}_{2} \mathrm{O}_{3}$ /carbon microstructure in the precursor using a condensed $\mathrm{H}_{3} \mathrm{BO}_{3}$-polyol product was outlined. We focused on the formation of a $\mathrm{B}-\mathrm{O}-\mathrm{C}$ bond by the dehydration condensation of $\mathrm{H}_{3} \mathrm{BO}_{3}$ and a polyol and the formation of the $\mathrm{B}_{2} \mathrm{O}_{3} /$ carbon structure by the thermal decomposition of a condensed product in air. The dispersion morphology of the $\mathrm{B}_{2} \mathrm{O}_{3} /$ carbon structure is the main factor determining the synthetic process of $\mathrm{B}_{4} \mathrm{C}$ powder. The improved dispersibility and homogeneity of the $\mathrm{B}_{2} \mathrm{O}_{3} /$ carbon microstructure was conducive to the accelerated $\mathrm{B}_{4} \mathrm{C}$ formation at lower temperatures, and the low-temperature synthesis of crystalline $\mathrm{B}_{4} \mathrm{C}$ powder with little free carbon was achieved. This approach is a promising methodology for the low-temperature synthesis of boride powders by carbothermal reduction.

Acknowledgements The author expresses his sincere gratitude to Professor Hidehiko Kobayashi and Associate Professor Ikuo Yanase (Saitama University) for their continuous support. The author also acknowledges students for their contributions to this work. This work was partly supported by a Grant-in-Aid for Young Scientists (B) (JP24750198 and JP16K21067) from the Japan Society for the Promotion of Science (JSPS), Sasakawa Scientific Research Grant from The Japan Science Society, and Nippon Sheet Glass Foundation for Materials Science and Engineering. 


\section{References}

1) K. A. Schwetz and A. Lipp, Ullmann's Encyclopedia of Industrial Chemistry, Fifth Ed., A4, VCH, Weinheim (1985) pp. 295-300.

2) F. Thevenot, J. Eur. Ceram. Soc., 6, 205-225 (1990).

3) A. K. Suri, C. Subramanian, J. K. Sonber and T. S. R. Ch. Murthy, Int. Mater. Rev., 55, 4-40 (2010).

4) H. Wada, S. Ito, K. Kuroda and C. Kato, Chem. Lett., 14, 691-692 (1985).

5) H. Wada, K. Kuroda and C. Kato, Yogyo-Kyokai-shi, 94, 61-65 (1986).

6) A. Sinha, T. Mahata and B. P. Sharma, J. Nucl. Mater, 301, 165-169 (2002).

7) A. K. Khanra, Bull. Mater. Sci., 30, 93-96 (2007).

8) A. M. Hadian and J. A. Bigdeloo, J. Mater. Eng. Perform., 17, 44-49 (2008).

9) H. Konno, A. Sudoh, Y. Aoki and H. Habazaki, Mol. Cryst. Liq. Cryst., 386, 15-20 (2002).

10) A. Sudoh, H. Konno, H. Habazaki and H. Kiyono, Tanso, 226, 8-12 (2007).

11) I. Hasegawa, Y. Fujii, T. Takayama and K. Yamada, J. Mater. Sci. Lett., 18, 1629-1631 (1999).

12) S. Mondal and A. K. Banthia, J. Eur. Ceram. Soc., 25, 287-291 (2005).

13) I. Yanase, R. Ogawara and H. Kobayashi, Mater. Lett., 63, 91-93 (2009).

14) M. Kakiage, N. Tahara, I. Yanase and H. Kobayashi, Mater. Lett., 65, 1839-1841 (2011).

15) M. Kakiage, N. Tahara, S. Yanagidani, I. Yanase and H. Kobayashi, J. Ceram. Soc. Jpn., 119, 422-425 (2011).

16) M. Kakiage, Y. Tominaga, I. Yanase and H. Kobayashi, Powder Technol., 221, 257-263 (2012).

17) M. Kakiage, N. Tahara, Y. Tominaga, S. Yanagidani, I.
Yanase and H. Kobayashi, Key Eng. Mat., 534, 61-65 (2013).

18) M. Kakiage, N. Tahara, R. Watanabe, I. Yanase and H. Kobayashi, J. Ceram. Soc. Jpn., 121, 40-44 (2013).

19) N. Tahara, M. Kakiage, I. Yanase and H. Kobayashi, J. Alloy. Compd., 573, 58-64 (2013).

20) H. Steinberg, Organoboron chemistry, Vol. 1, Boronoxygen and boron-sulfur compounds, John Wiley \& Sons Inc., New York (1964).

21) P. M. Barros, I. V. P. Yoshida and M. A. Schiavon, J. Non-Cryst. Solids, 352, 3444-3450 (2006).

22) S. J. Yoon and A. Jha, J. Mater. Sci., 31, 2265-2277 (1996).

23) M. Rezvani, A. R. Aghaei and F. Moztarzadeh, Ind. Ceram., 19, 156-159 (1999).

24) A. Aydoğdu and N. Sevinç, J. Eur. Ceram. Soc., 23, 3153-3161 (2003).

25) H. E. Çamurlu, N. Sevinç and Y. Topkaya, J. Mater Sci., 41, 4921-4927 (2006).

26) M. Kakiage, T. Shoji and H. Kobayashi, J. Ceram. Soc. Jpn., 124, 13-17 (2016).

27) S. Zheng, G. Min, Z. Zou, H. Yu and J. Han, J. Am. Ceram. Soc., 84, 2725-2727 (2001).

$28)$ L. Zhang, G. Min, H. Yu, H. Chen and G. Feng, Key Eng. Mat., 326-328, 369-372 (2006).

29) L. Zhang, G. Min and H. Yu, Ceram. Int., 35, 35333536 (2009).

30) Ö. Yildiz, R. Telle, C. Schmalzried and A. Kaiser, J. Eur. Ceram. Soc., 25, 3375-3381 (2005).

31) M. Kakiage, S. Shiomi, I. Yanase and H. Kobayashi, J. Am. Ceram. Soc., 98, 2724-2727 (2015).

32) M. Kakiage, S. Shiomi, T. Ohashi and H. Kobayashi, Adv. Powder Technol., 29, 36-42 (2018).

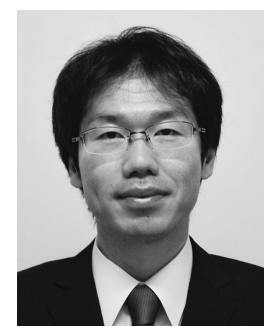

Masaki Kakiage is an Assistant Professor at Institute for Fiber Engineering, Shinshu University (IFES), Interdisciplinary Cluster for Cutting Edge Research (ICCER), Shinshu University. He received his Ph.D. in Engineering from Gunma University in 2008. He was a Research Fellow of Japan Society for the Promotion of Science (JSPS) in 2007-2009. He joined Tokyo Institute of Technology as a postdoctoral fellow in 2008-2009. He worked at Graduate School of Science and Engineering, Saitama University as an Assistant Professor in 2009-2015. He has been working as an Assistant Professor in Shinshu University since 2015. His research interests include the low-temperature synthesis of boride powders and the fabrication of nanostructured ceramics derived from organic compounds. 